Int. J. Electrochem. Sci., 12 (2017) $475-484$

International Journal of

ELECTROCHEMICAL

SCIENCE

WWw.electrochemsci.org

\title{
Highly Sensitive Determination of Folic Acid Using Graphene Oxide Nanoribbon Film Modified Screen Printed Carbon Electrode
}

\author{
Veerappan Mani ${ }^{1,2}$, Rajaji Umamaheswari ${ }^{3}$, Shen-Ming Chen ${ }^{1, *}$, Mani Govindasamy ${ }^{1}$, \\ Chaochin Su ${ }^{3}$, Anandaraj Sathiyan ${ }^{4}$,Johnson Princy Merlin ${ }^{4}$, Murugan Keerthi ${ }^{5}$ \\ ${ }^{1}$ Department of Chemical Engineering and Biotechnology, National Taipei University of Technology, \\ Taipei, Taiwan 106 (ROC) \\ ${ }^{2}$ Graduate Institute of Biomedical and Biochemical Engineering, National Taipei University of \\ Technology, Taipei, Taiwan (ROC) \\ ${ }^{3}$ Institute of Organic and Polymeric Materials, National Taipei University of Technology, Taipei \\ 10608, Taiwan \\ ${ }^{4}$ Department of Chemistry, Bishop Heber College (Autonomous), Tiruchirappalli-620 017, Tamil \\ $\mathrm{Nadu}$, India \\ ${ }^{5}$ Department of Analytical Chemistry, University of Madras, Guindy Campus, Chennai-600 025, \\ Tamil Nadu, India \\ *E-mail: smchen78@ms15.hinet.net
}

doi: $10.20964 / 2017.01 .34$

Received: 15 October 2016 / Accepted: 9 November 2016 / Published: 12 December 2016

\begin{abstract}
A cost-effective screen printed electrode modified with graphene oxide nanoribbon (GONR) is developed for the determination of folic acid (FA). GONR is prepared from multi-walled carbon nanotubes (MWCNTs) and our studies revealing that the electrocatalytic ability of MWCNTs is greatly improved in GONR. The GONR is successfully characterized by SEM, EDX and impedance analysis. Next, GONR was deposited on the pretreated screen printed carbon electrode (SPCE) and the resulting GONR/SPCE was used to study the electrocatalysis of FA. The fabricated modified electrode has excellent electrocatalytic ability to detect FA. The effect of scan rate and $\mathrm{pH}$ towards electrocatalysis of FA is studied in detailed. The electrode detects FA in wide linear range of $0.1-1600 \mu \mathrm{M}$ and achieves low detection limit of $20 \mathrm{nM}$. The sensor performance of the GONR/SPCE is either superior or comparable to the previously published FA sensors. Moreover, the electrode has good repeatability, reproducibility, stability and practicality.
\end{abstract}

Keywords: Two dimensional layered sheets, Graphene, Nanotechnology, Vitamins, Food science, Sensor, Analytical Chemistry 


\section{FULL TEXT}

(C) 2017 The Authors. Published by ESG (www.electrochemsci.org). This article is an open access article distributed under the terms and conditions of the Creative Commons Attribution license (http://creativecommons.org/licenses/by/4.0/). 